\title{
Designing materials and devices to revolutionize and engineer the future of electronics and photonics through computationally led and data-driven approaches
}

John Schlueter

John A. Schlueter, "Designing materials and devices to revolutionize and engineer the future of electronics and photonics through computationally led and data-driven approaches," Proc. SPIE 10639, Micro- and Nanotechnology Sensors, Systems, and Applications X, 106390B (8 May 2018); doi: $10.1117 / 12.2305496$ 


\title{
Designing Materials and Devices to Revolutionize and Engineer the Future of Electronics and Photonics through Computationally-led and Data-Driven Approaches
}

\author{
John A. Schlueter*a \\ ${ }^{a}$ National Science Foundation, 2415 Eisenhower Avenue, Alexandria, VA, USA 22314
}

\begin{abstract}
The Materials Genome Initiative (MGI) is a multi-agency partnership that seeks to accelerate the pace of materials development across the Materials Development Continuum. Through use of a computationally-led and data-driven approach, MGI promotes the rapid discovery and deployment of advanced materials that will ensure sustained American leadership in sectors including energy, electronics, and photonics. The goals of the MGI include 1) leading a culture shift in materials research through use of an iterative feedback-loop approach, 2) integrating experiment, computation, and theory throughout the materials research community, 3) making digital data accessible and useful to the larger community, and 4) creating a world-class materials science and engineering workforce. The Designing Materials to Revolutionize and Engineer our Future (DMREF) program at the National Science Foundation (NSF) partners with a number of other federal funding agencies to promote these objectives. DMREF includes participation from ten divisions in three directorates at the NSF to address fundamental materials discovery and development. This program currently funds about one hundred projects that cover the full spectrum of materials research. Among these are a number of projects that focus on electronic and photonic materials and devices in both the organic and inorganic realms. Graphenebased origami and kirigami metamaterials are among those being developed thought this methodology. The principles of the MGI are described and examples from specific DMREF projects are provided.

Keywords: Materials Genome Initiative (MGI), Designing Materials to Revolutionize and Engineer our Future (DMREF), electronic materials, photonic materials, origami, kirigami
\end{abstract}

\section{INTRODUCTION}

Advanced materials are essential for economic security and human well-being, with applications in multiple industries, including those aimed at addressing challenges in clean energy, national security, and human welfare. The Materials Genome Initiative (MGI) for Global Competitiveness was announced on June 24, 2011 with the goal of doubling the speed and reducing the cost of discovering, developing, and deploying new advanced materials [1]. Through the use of traditional approaches, it can often take decades for a newly discovered material to be commercialized. This pace is much too slow to maintain global competitiveness and to address urgent material challenges necessary to improve societal needs. MGI aims to capitalize on recent breakthroughs in materials modeling, theory, and data mining to significantly accelerate discovery and deployment of advanced materials while decreasing their cost. The National Science Foundation's primary (though not only) response to the MGI is the Designing Materials to Revolutionize and Engineer our Future (DMREF) program, which is addressed here.

\section{THE MATERIALS GENOME INITIATIVE (MGI)}

The MGI evolved from the Integrated Computational Materials Engineering (ICME) approach to research [2]. At the heart of the MGI is the Materials Innovation Infrastructure (Figure 1), a framework of seamlessly integrating the advanced modeling, data, and experimental tools that will be used to attain the MGI vision. As described in the MGI strategic plan, achieving this vision requires successfully addressing four key challenges [3]: 1) Leading a culture shift in materials research to encourage and facilitate an integrated team approach that links computation, data, and experiment and crosses boundaries between academia, National and Federal laboratories, and industry; 2) Integrating experiment, computation, and theory and equipping the materials community with the advanced tools and techniques to work across materials classes and along the materials development continuum from research to industrial application; 3) Making digital data accessible including combining data from experiment and computation into a searchable materials data infrastructure and encouraging researchers to make their data available to others; and 4) Creating a world-class materials

Micro- and Nanotechnology Sensors, Systems, and Applications X, edited by Thomas George,

Achyut K. Dutta, M. Saif Islam, Proc. of SPIE Vol. 10639, 106390B - @ 2018 SPIE

CCC code: $0277-786 \mathrm{X} / 18 / \$ 18 \cdot$ doi: $10.1117 / 12.2305496$ 
workforce that is trained for careers in academia or industry, including high-tech manufacturing jobs. A key concept for the MGI is to seamlessly move concepts, processes, materials, and devices along the Materials Development Continuum toward eventual deployment. This Continuum takes the fundamental discovery through development, property optimization, systems design and integration, certification, and manufacturing to reach deployment. A tight iterative feedback loop is required to accelerate this process.
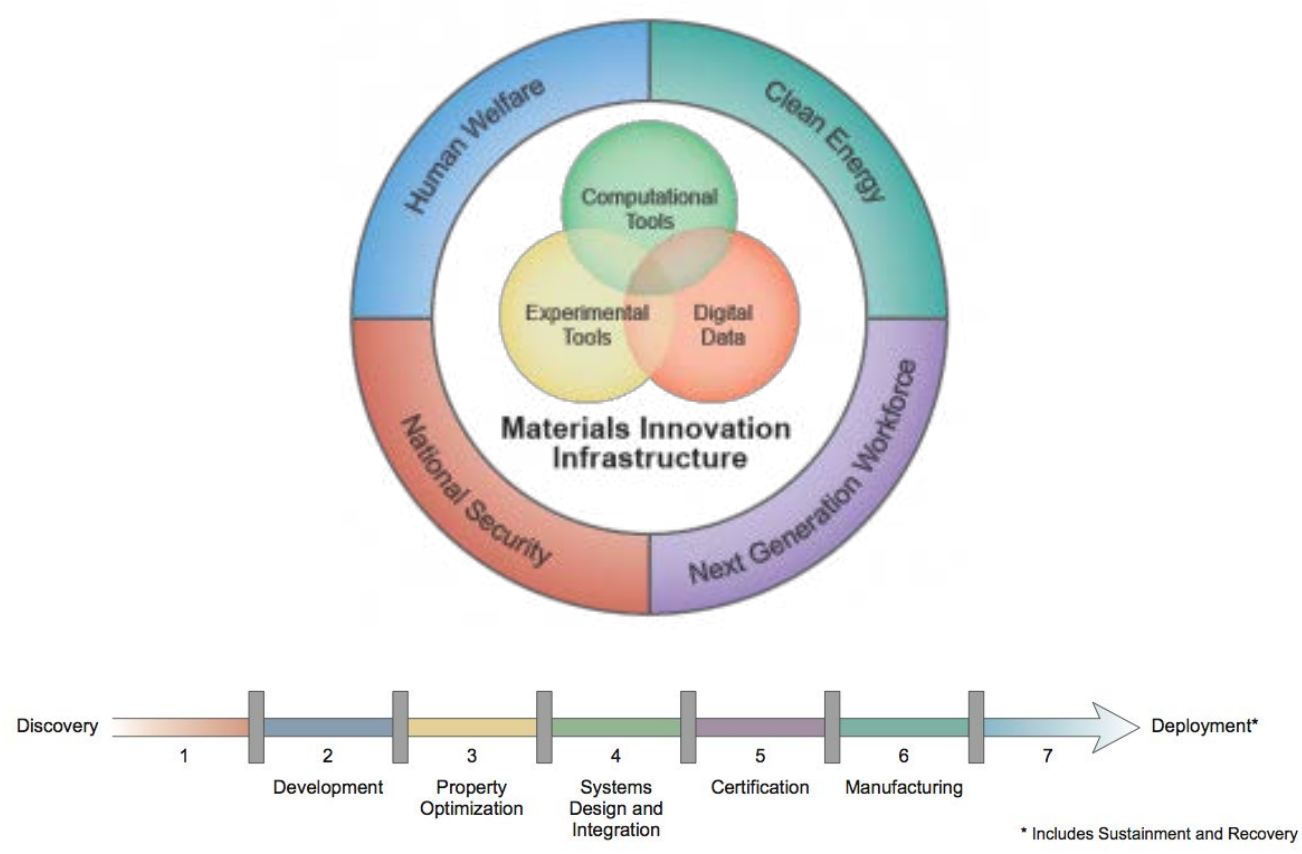

Figure 1. (top) The Materials Genome Initiative is working to develop a Materials Innovation Infrastructure by which computational tools, experimental tools, and digital data work hand-in-hand to address issues including human welfare, clean energy, national security, and the development of the next generation workforce. (bottom) The Materials Development Continuum describes the path from fundamental discoveries to eventual deployment. Taken from [3].

The fifth anniversary of the MGI was celebrated in 2016 by White House officials, the Department of Defense (DoD), the Department of Energy (DOE), the National Institute of Standards and Technology (NIST), the National Aeronautics and Space Administration (NASA) and the National Science Foundation (NSF), along with leading experts from industry, academia, and government. Over the first five years, over $\$ 500$ million has been invested in resources and infrastructure in support of this Initiative. At that time, a selection of accomplishments and technical highlights were identified relating to each of the four primary challenges identified for the MGI.

Principal Investigators (PIs) from MGI-related research projects funded through various federal agencies meet on an approximately annual basis. The first DMREF Grantees Workshop was held in September 2013 in Arlington, VA, with a report from this meeting, including several technical highlights, published shortly thereafter [5]. Subsequent MGI PI Meetings have included participants from multiple federal agencies. Extensive Conference Proceedings from the second and third MGI PI Meetings are electronically available [6,7].

\section{DESIGNING MATERIALS TO REVOLUTIONIZE AND ENGINEER OUR FUTURE (DMREF)}

NSFs DMREF program began as a Dear Colleague Letter (NSF 11-089) with fourteen projects funded in 2012. In 2014, DMREF became an official NSF program through solicitation NSF 14-591, and continued through NSF 15-608 and NSF 16-613. DMREF is the primary program by which the NSF participates in the MGI. DMREF supports activities that accelerate materials discovery and development by building the fundamental knowledge base needed to design and make materials with specific and desired functions or properties from first principles. This is accomplished by understanding 
the interrelationships of composition, structure, properties, processing, and performance. Achieving this goal involves modeling, analysis, and computational simulations, validated and verified through sample preparation, characterization, and device demonstration. It requires new data analytic tools and statistical algorithms; advanced simulations of material properties in conjunction with new device functionality; advances in predictive modeling that leverage machine learning, data mining, and sparse approximation; data infrastructure that is accessible, extensible, scalable, and sustainable; the development, maintenance, and deployment of reliable, interoperable, and reusable software for the next-generation design of materials; and new collaborative capabilities for managing large, complex, heterogeneous, distributed data supporting materials design, synthesis, and longitudinal study. DMREF aligns with national priorities for advanced manufacturing and future industries, national defense and homeland security, information technologies and high performance computing, human health and welfare, clean energy, and Science, Technology, Engineering, and Mathematics.

The multidisciplinary character of this effort dictates the involvement of various divisions in the NSF Directorates of Mathematical and Physical Sciences, Engineering, and Computer and Information Science and Engineering. Due to the highly interdisciplinary nature of the program, a significant fraction of projects ( $75 \%)$ attract co-funding from multiple divisions. DMREF is managed by a team of program directors from these various divisions.

In addition to the standard NSF merit review criteria associated with intellectual merit and broader impact, DMREF proposals are also evaluated according to their potential to: 1) accelerate materials discovery and development by building the fundamental knowledge base needed to progress toward designing and making materials with specific, desired functions or properties, 2) use collaborative processes with iterative feedback between tasks, 3) provide training for the next generation of scientists and engineers, educated in a multidisciplinary, integrated experimental and computational approach to materials research, and 4) provide open access to its outputs, including data, software, codes, samples, and publications.

NSF's DMREF program promotes workforce development by providing graduate students and post-docs with a broad education through co-advising and student exchange within multi-disciplinary teams consisting of synthetic, experimental, and theoretical expertise. New courses have been developed to educate students on methods that promote accelerated materials development, including targeted high-throughput experimental and computational approaches. Symposia have been organized at national scientific conferences in order to educate the community on MGI strategies. Emphasis is given to coordinated outreach activities whereby underrepresented groups, K-12 students, and the general public share the excitement of new materials discovery and development. Modern tools, such as youtube videos, have been utilized to promote research accomplishments to a tech-savvy audience.

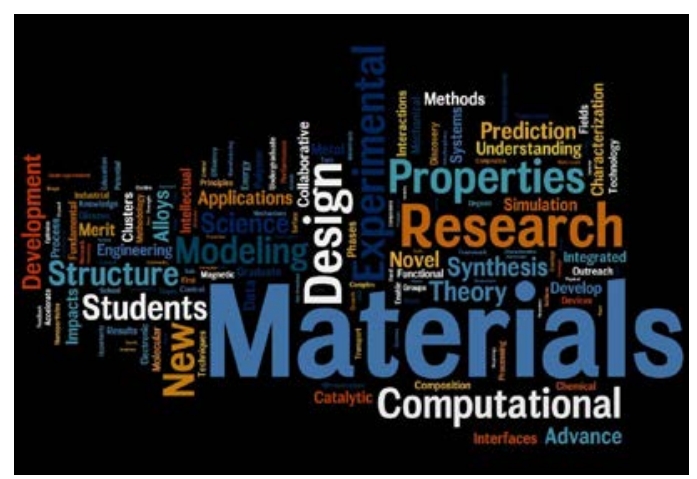

Figure 2. Word cloud derived from terms used in abstracts of DMREF projects, demonstrating the importance of synthesis, experiment, and theory, as well as education, in the discovery and development of new materials.

With a solid base of projects established through annual competitions, the DMREF program has evolved to a biennial competition. Whereas, early projects were often funded for three years, due to the complexity of engaging a collaborative set of researchers (often over multiple campuses), future DMREF projects will be funded for four years. The DMREF program encompasses the full range of material classes as described by the MGI Strategic Plan, including biomaterials, catalysts, polymer composites, correlated materials, electronic and photonic materials, energy storage systems, lightweight and structural materials, organic electronic materials, and polymers. Some of the important components of DMREF are illustrated by a word cloud in Figure 2. To date, DMREF has funded 139 projects that have involved 528 PIs, with a total investment of \$172 M. 


\section{ELECTRONIC AND PHOTONIC MATERIALS: OPPORTUNITIES FOR ORIGAMI AND KIRIGAMI}

The MGI Strategic Plan [3] notes that devices and components produced by the electronics and photonics industries are crucial to almost any application, including the MGI pillars of national security, energy, and human welfare. Improvements to electronic and photonic materials, as well as to the manufacturing processes used to produce devices, are necessary to support continued performance improvements. A goal of MGI is thus to discovery new processes, materials, and device structures related to electronic and photonic needs and to accelerate the advancement of these fundamental discoveries along the materials development continuum. Fundamental technologies developed through MGI-related programs such as NSF's DMREF or DOE's Basic Energy Sciences (BES) Computational Science Centers can smoothly be translated to more applied funding streams including the DOE's Energy Materials Network (ENM) or the Department of Defense's (DoD's) research laboratories such as the Air Force Research Laboratory (AFRL), Army Research Laboratory (ARL), and Office of Naval Research (ONR). Some of the grand challenge identified for this class of materials include [3]:

1) Prediction of excited states, transport, and non-equilibrium structures in electronic materials.

2) Demonstration of highly accurate theories and methods for modeling electrical or optical properties of materials in structures smaller than $10 \mathrm{~nm}$.

3) Establishment of predictive models of full-device, emergent, or system properties through use of inputs from material properties, modes of integration, processing history, structural or defect attributes, and spatial or geometric features.

4) Development of models and validation of data to enable transition from bench-type design to design of a fabricated component with existing equipment.

5) Implementation of tools that progressively validate, and render transparent, materials-centric databases.

6) Modeling and prediction of the properties of a device, circuit, or electronic system at production scale through use of information only obtained at research scale.

7) Modeling and prediction of the part-to-part variability of production devices as a function of material features and processing.

Origami and kirigami, the arts of folding and cutting paper, offer a powerful new pathway to nanoscale materials design. Fitting well with the MGI approach, theoretical models can provide guidance in selecting design parameters in the development of functional materials. The DMREF project 'Laminated Elastomer Composites with Anisotropic Shape Memory' by Pat Mather and Jerry Qi have investigated active origami by 4D printing [8]. Active materials, such as shape memory polymers, can be 3D printed to create active microstructures within a solid and can subsequently be activated in a controlled manner to change the shape or configuration in response to an environment stimuli.

Two DMREF projects are addressing the use of DNA origami for the arrangement of nanoparticles for optoelectronic applications. The project 'Self Assembly with DNA-labeled Colloidal Particles and DNA Nanostructures' by Michael Brenner, Vinothan Manoharan, and William Shih have reported a strategy for assembling three-dimensional nanoparticle clusters that use a molecular frame designed with encoded vertices for particle placement. The frame is a DNA origami octahedron and can be used to fabricate clusters with various symmetries and particle compositions. The DNA frame and one set of nanoparticles can be used to create nanoclusters with different chiroptical activities [9]. The project 'Computational Design Principles for Functional DNA-materials' by Mark Bathe, Hao Yan, and Peng Yin has significantly broadened the ability to predict 3D geometry of complex DNA nanostructures from linear sequences [10] and have demonstrated the ability to computationally design sub-10 nm metallic particles with geometries and optical properties that are specified using these DNA molds [11]. The team has reported a design strategy for fabricating finitesized wireframe DNA nanostructures with high complexity and programmability [12] and have described a framework to design and synthesize a single DNA or RNA strand to self-fold into a complex yet unknotted structure that approximates an arbitrary user-prescribed shape [13]. The team has designed a family of hexagonal DNA-origami tiles through use of computer aided design and have demonstrated successful self-assembly of micrometer-scale 2D honeycomb lattices and tubes by controlling their geometric and mechanical properties, including their interconnecting strands. Their results offer insight into programmed self-assembly of low-defect supra-molecular DNA origami 2D lattices and tubes. In addition, they demonstrated that these DNA-origami hexagon tiles and honeycomb lattices are versatile platforms for assembling optical metamaterials via programmable spatial arrangement of gold nanoparticles into cluster and superlattice geometries [14]. Together, these findings demonstrate the ability to perform rational in-silico design of functional nanoscale materials. 
Table 1. Representative DMREF projects, related to Electronic and Photonic Materials, that have been funded in the past two years. Details on earlier projects can be found in the extended abstracts that are compiled in the MGI PI Meeting Proceedings [6,7].

\begin{tabular}{|c|c|c|}
\hline Project Title & Principal Investigators & Institution \\
\hline $\begin{array}{l}\text { Organic Semiconductors by Computationally- } \\
\text { Accelerated Refinement (OSCAR) }\end{array}$ & $\begin{array}{l}\text { John Anthony } \\
\text { Chad Risko } \\
\text { Lynn Loo } \\
\text { Oana Jurchescu }\end{array}$ & $\begin{array}{l}\text { University of Kentucky } \\
\text { Princeton University } \\
\text { Wake Forest University }\end{array}$ \\
\hline Doping and Defects in Diamond for Electronics & $\begin{array}{l}\text { Timothy Grotjohn } \\
\text { John Albrecht } \\
\text { Thomas Schuelke } \\
\text { Greg Swain }\end{array}$ & Michigan State University \\
\hline $\begin{array}{l}\text { Design rules for flexible conductors: predicting } \\
\text { chain conformations, entanglements, and liquid } \\
\text { crystalline phases of conjugated polymers }\end{array}$ & $\begin{array}{l}\text { Enrique Gomez } \\
\text { Ralph Colby } \\
\text { Scott Milner }\end{array}$ & Pennsylvania State University \\
\hline $\begin{array}{l}\text { Semiconductor Heterostructure Platform for Active } \\
\text { Nonlocal Plasmonic and Hyperbolic Materials }\end{array}$ & $\begin{array}{l}\text { Viktor Podolskiy } \\
\text { Claire Grachl } \\
\text { Evgeniy Narimanov } \\
\text { Daniel Wasserman }\end{array}$ & $\begin{array}{l}\text { University of Massachusetts- } \\
\text { Lowell } \\
\text { Princeton University } \\
\text { Purdue University } \\
\text { University of Texas-Austin }\end{array}$ \\
\hline $\begin{array}{l}\text { Materials Design of Correlated Metals as Novel } \\
\text { Transparent Conductors }\end{array}$ & $\begin{array}{l}\text { Roman Engel-Herbert } \\
\text { Venkatraman Gopalan } \\
\text { Turan Birol } \\
\text { Karin Rabe } \\
\mathrm{Ni} \mathrm{Ni}\end{array}$ & $\begin{array}{l}\text { Pennsylvania State University } \\
\text { University of Nebraska- } \\
\text { Lincoln } \\
\text { Rutgers University } \\
\text { UCLA }\end{array}$ \\
\hline $\begin{array}{l}\text { Tackling Disorder and Ensemble Broadening in } \\
\text { Materials Made of Semiconductor Nanostructures }\end{array}$ & $\begin{array}{l}\text { Dmitri Talapin } \\
\text { Evan Rabani } \\
\text { Richard Schaller }\end{array}$ & $\begin{array}{l}\text { University of Chicago } \\
\text { University of California- } \\
\text { Berkeley } \\
\text { Northwestern University } \\
\end{array}$ \\
\hline $\begin{array}{l}\text { Nanoscale Temperature Manipulation via } \\
\text { Plasmonic Fano Interferences }\end{array}$ & $\begin{array}{l}\text { David Masiello } \\
\text { Stephan Link } \\
\text { Katherine Willets }\end{array}$ & $\begin{array}{l}\text { University of Washington } \\
\text { Rice University } \\
\text { Temple University }\end{array}$ \\
\hline $\begin{array}{l}\text { HybriD3: Discovery, Design, Dissemination of } \\
\text { Organic-Inorganic Hybrid Semiconductor } \\
\text { Materials for Optoelectronic Applications }\end{array}$ & $\begin{array}{l}\text { Volker Blum } \\
\text { David Mitzi } \\
\text { Wei You } \\
\text { Yosuke Kanai } \\
\text { Kenan Gundogdu } \\
\text { Franky So }\end{array}$ & $\begin{array}{l}\text { Duke University } \\
\text { University of North Carolina- } \\
\text { Chapel Hill } \\
\text { North Carolina State } \\
\text { University }\end{array}$ \\
\hline Structure Genome of Metal-Insulator Transitions & $\begin{array}{l}\text { James Rondinelli } \\
\text { Stephen Wilson } \\
\text { Ram Seshadri } \\
\text { Susanne Stemmer } \\
\end{array}$ & $\begin{array}{l}\text { Northwestern University } \\
\text { University of California-Santa } \\
\text { Barbara }\end{array}$ \\
\hline $\begin{array}{l}\text { Metallic-type Transport in Polymers: Establishing } \\
\text { Materials Design Criteria and Predicting } \\
\text { Structure/property Interrelations }\end{array}$ & $\begin{array}{l}\text { Natalie Stingelin } \\
\text { Alejandro Briseno } \\
\text { Seth Marder } \\
\text { Carlos Silva } \\
\end{array}$ & $\begin{array}{l}\text { Georgia Tech. } \\
\text { University of Massachusetts- } \\
\text { Amherst }\end{array}$ \\
\hline $\begin{array}{l}\text { Synthesis, Characterization, and Modeling of } \\
\text { Complex Amorphous Semiconductors for Future } \\
\text { Device Applications }\end{array}$ & $\begin{array}{l}\text { Julie Medvedeva } \\
\text { Robert Chang } \\
\text { Matthew Grayson }\end{array}$ & $\begin{array}{l}\text { Missouri University of Science } \\
\text { and Technology } \\
\text { Northwestern University }\end{array}$ \\
\hline
\end{tabular}

The DMREF project 'Graphene Based Origami and Kirigami Metamaterials', by Itai Cohen, Paul McEuen, Mark Bowik, and David Nelson, was funded in the class of 2014. Drawing inspiration from optical and acoustic metamaterials, the 
team is developing a framework for designing and fabricating atomic membrane origami and kirigami metamaterials. Using lithographic techniques, graphene sheets can be perforated and cut to create modules with prescribed mechanical properties. These modules will then be assembled to create mechanical metamaterials whose response to applied stresses, temperature, and other environmental signals can be tailored. Several relevant papers have been published under this award [15-18].

Representative DMREF projects related to electronic and photonic processes, materials, and devices from the classes of 2016 and 2017 are listed in Table 1.

\section{CONCLUSIONS}

In its first seven years, the Materials Genome Initiative has demonstrated the ability to accelerate materials research through computationally-driven research. The National Science Foundation's Designing Materials to Revolutionize and Engineer our Future (DMREF) program brings together principle investigators to closely integrate computational design, synthesis/processing, and experiment in tight iterative feedback loops. Although DMREF spans the full materials spectrum, a significant amount of impactful work is being performed in the area of electronic and photonic materials, processes, and devices, including efforts to couple the ancient arts of origami and kirigami to the computationally-led design strategy of these materials. As this research philosophy heads toward its tenth anniversary, data-driven methods are becoming increasingly important to take this research to the next level. These efforts extend across various federal agencies in order to translate fundamental discoveries along the materials development continuum toward eventual deployment.

\section{REFERENCES}

[1] OSTP: Materials Genome Initiative for Global Competitiveness. June 2011. https://www.mgi.gov/sites/default/files/documents/materials genome_initiative-final.pdf

[2] National Research Council, Integrated Computational Materials Engineering: A Transformational Discipline for Improved Competitiveness and National Security, (2008) Washington, D.C.: The National Academies Press. (available online at http://www.nap.edu/catalog.php?record_id=12199).

[3] Materials Genome Initiative Strategic Plan https://www.mgi.gov/sites/default/files/documents/mgi_strategic_plan_dec 2014.pdf

[4] The First Five Years of the Materials Genome Initiative: Accomplishments and Technical Highlights https://mgi.nist.gov/sites/default/files/uploads/mgi-accomplishments-at-5-years-august-2016.pdf

[5] Feldman, K. and Agnew, S., "The Materials Genome Initiative at the National Science Foundation: A Status Report after the First Year of Funded Research" JOM 66, 336-344 (2014).

[6] DOE/NSF Materials Genome Initiative, 2 ${ }^{\text {nd }}$ Annual Principal Investigator Meeting, Accelerating Materials Research, Meeting Societal Needs, Building Infrastructure for Success, Bethesda, MD, January 12-13, 2015. https://www.mgi.gov/sites/default/files/documents/2015_MGI_PI_Meeting_Abstract_Book.pdf

[7] Materials Genome Initiative, Accelerating Materials Research, Third Principal Investigator Meeting, Bethesda, MD, January 11-12, 2016. https://www.mgi.gov/sites/default/files/documents/2016_Abstract_Book_Final.pdf

[8] Q. Ge, C. K. Dunn, H. J. Qi et al., “Active Origami by 4D Printing,” Smart Materials and Structures, 23(9), 094007 (2014).

[9] Y. Tian, T. Wang, W. Y. Liu et al., "Prescribed Nanoparticle Cluster Architectures and Low-dimensional Arrays built using Octahedral DNA Origami Frames,” Nature Nanotechnology, 10(7), 637 (2015).

[10] K. Y. Pan, D. N. Kim, F. Zhang et al., "Lattice-free Prediction of Three-dimensional Structure of Programmed DNA Assemblies,” Nature Communications, 5, 5578 (2014).

[11]W. Sun, E. Boulais, Y. Hakobyan et al., “Casting Inorganic Structures with DNA Molds,” Science, 346(6210), 717 (2014).

[12]F. Zhang, S. X. Jiang, S. Y. Wu et al., "Complex Wireframe DNA Origami Nanostructures with Multi-arm Junction Vertices,” Nature Nanotechnology, 10(9), 779 (2015).

[13]D. R. Han, X. D. Qi, C. Myhrvold et al., "Single-stranded DNA and RNA Origami," Science, 358(6369), 1402 (2017). 
[14]P. F. Wang, S. Gaitanaros, S. Lee et al., "Programming Self-Assembly of DNA Origami Honeycomb TwoDimensional Lattices and Plasmonic Metamaterials,” Journal of the American Chemical Society, 138(24), 77337740 (2016).

[15]M. J. Bowick, A. Kosmrlj, D. R. Nelson et al., "Non-Hookean Statistical Mechanics of Clamped Graphene Ribbons,” Physical Review B, 95(10), 104109 (2017).

[16] A. Kosmrlj, and D. R. Nelson, "Response of Thermalized Ribbons to Pulling and Bending," Physical Review B, 93(12), 125431 (2016).

[17]E. R. Russell, R. Sknepnek, and M. Bowick, "Stiffening Thermal Membranes by Cutting," Physical Review E, 96(1), 013002 (2017).

[18]D. D. Wan, D. R. Nelson, and M. J. Bowick, “Thermal Stiffening of Clamped Elastic Ribbons,” Physical Review B, 96(1), 014106 (2017). 